\title{
A influência da publicidade da indústria alimentícia nos hábitos alimentares infantis: uma revisão bibliográfica
}

The influence of food industry advertising on children's eating habits: a literature review

La influencia de la publicidad de la industria alimentaria en los hábitos alimentarios de los niños: uma revisión de la literatura

Recebido: 01/11/2021 | Revisado: 07/11/2021 | Aceito: 09/11/2021 | Publicado: 12/11/2021

Elizete Nunes da Silva

ORCID: https://orcid.org/0000-0002-1452-8899

Faculdade Integrada Carajás, Brasil

E-mail: elizetenunes017@gmail.com

Geane Dias de Almeida

ORCID: https://orcid.org/0000-0002-0313-0594 Faculdade Integrada Carajás, Brasil E-mail: geanediasalmeida30@gmail.com

Alessandra Gomes Skrivan

ORCID: https://orcid.org/0000-0001-9917-0082 Faculdade Integrada Carajás, Brasil E-mail: skrivan_lua@hotmail.com

\begin{abstract}
Resumo
O presente estudo discorre sobre a atuação da propaganda da indústria alimentícia nos costumes alimentares infantis. O avanço tecnológico vivido pela sociedade atual traz transformações no padrão de vida sem precedentes, sendo assim, é preciso estar atento ao uso dessas tecnologias na infância. Nesse sentido, as campanhas publicitárias que envolvem alimentos fazem parte cada vez mais cedo do mundo da criança influenciando seu hábito alimentar. O estudo tem comoobjetivo discorrer sobre a atuação da publicidade sobre as escolhas alimentares voltadas ao público infante. Para isso, foi realizada uma revisão bibliográfica integrativa de caráter descritivo com abordagem qualitativa. Como fonte de dados foram utilizadas revistas eletrônicas e livros com corte temporal de 2015 a 2021 que abordam a temática proposta. Evidenciou que a divulgação em mídias digitais não possui fiscalização na qual asseguram as normativas brasileiras e que as crianças pouco têm acompanhamento das famílias no acesso à rede, ficando as mesmas suscetíveis a influência de campanhas que abordam uma alimentação não saudável. Em detrimento de uma alimento inadequada sem nutrientes e de muito tempo diante da tela, essas crianças ganham gordura podendo chegar a obesidade infantil, o que é um problema de saúde pública na atualidade. Por ser uma fase de desenvolvimento físico e cognitivo é imprescindível que a criança tenha hábito alimentar saudável e que faça atividades físicas, portanto, as brincadeiras de bola, correr, subir, entre outras, são fundamentais para manter a saúde e qualidade de vida da criança.
\end{abstract}

Palavras-chave: Marketing de alimentos infantis; Publicidade de alimentos industrializados; Influência da mídia na alimentação.

\begin{abstract}
This study discusses the influence of advertising in the food industry on children's eating habits. The technological advance experienced by today's society brings unprecedented changes in the standard of living, so it is necessary to be aware of the use of these technologies in childhood. In this sense, advertising campaigns involving food are increasingly part of the child's world, influenced by their eating habits. The study aims to discuss the influence of advertising on food choices aimed at children. For this, an integrative bibliographic review of descriptive character with a qualitative approach was carried out. As a data source, electronic journals and books with a time cut from 2015 to 2021 that address the proposed theme were used. It showed that advertising in digital media does not have supervision in which Brazilian regulations ensure and that children have little monitoring by their families in accessing the network, making them susceptible to the influence of campaigns that address unhealthy eating. At the expense of an inadequate diet without nutrients and a long time spent in front of the screen, these children gain fat and can reach childhood obesity, which is a public health problem today. As it is a phase of physical and cognitive development, it is essential that the child has ahealthy eating habit and that they do physical activities, therefore, ball games, running, climbing, among others, are essential to maintain the child's health and quality of life.
\end{abstract}

Keywords: Children's food marketing; Adverstising of processed foods; Media influence on food. 


\section{Resumen}

Este estudio analiza la influencia de la publicidad en la industria alimentaria en los hábitos alimentarios de los niños. Elavance tecnológico que vive la sociedad actual trae consigo cambios sin precedentes en el nivel de vida, por lo que es necesario estar pendiente del uso de estas tecnologías en la infancia. En este sentido, las campañas publicitarias relacionadas con la alimentación son cada vez más parte del mundo del niño, influenciado por sus hábitos alimentarios. El estudio tiene como objetivo discutir la influencia de la publicidad en la elección de alimentos dirigida a los niños. Para ello, se realizó una revisión bibliográfica integradora de carácter descriptivo con un enfoque cualitativo. Como fuente de datos, se utilizaron revistas y libros electrónicos con un corte de tiempo de 2015 a 2021 que abordan el tema propuesto. Mostró que la publicidad en los medios digitales no tiene una supervisión en la que aseguran las regulacionesbrasileñas y que los niños tienen poco control por parte de sus familias en el acceso a la red, lo que los hace susceptiblesa la influencia de campañas que abordan la alimentación no saludable. A costa de una alimentación inadecuada sin nutrientes y un largo tiempo frente a la pantalla, estos niños engordan y pueden llegar a la obesidad infantil, que es un problema de salud pública en la actualidad. Al ser una fase del desarrollo físico y cognitivo, es fundamental que el niñotenga un hábito de alimentación saludable y que realice actividades físicas, por ello, los juegos de pelota, correr, escalar,entre otros, son fundamentales para mantener la salud y la calidad de la vida del niño.

Palabras clave: Marketing de alimentos para niños; Publicidad de alimentos processados; Influencia de los medios enla comida.

\section{Introdução}

No Brasil, a Carta Magna de 1988, que é a lei maior do país, assegura o direito à saúde e a alimentação como direitos fundamentais descritos no capítulo destinado aos direitos sociais. A alimentação saudável e balanceada é uma condicionalidadebásica para a promoção e proteção da saúde de indivíduos e coletividades (Brasil, 1988).

A saúde coletiva é uma estratégia de abordagem das questões de saúde das diferentes populações e comunidades que compõem a sociedade brasileira. Através da atuação da Vigilância em Saúde, dos sistemas de informação em saúde e dos serviçosde Atenção Básica na Atenção Primária à Saúde, evidenciou-se que a incidência e prevalência da obesidade e demais distúrbiosalimentares podem ser observados no decorrer dos últimos anos, trazendo o alerta para os órgãos competentes de saúde (Jardim\& Souza, 2017).

A publicidade de alimentos em mídias é algo frequente e considerado comum, no entanto, quando se trata de crianças é preciso tomar ciência da influência persuasiva na decisão quanto aos alimentos a serem ingeridos pelo público infantil. As marcas investem em propagandas atrativas, geralmente envolvendo personagens conhecidos, o que contribui para aceitação do material divulgado. Porém, é importante elucidar que no Brasil, apesar de não haver leis específicas que regulamentam essas campanhas, existem normativas que abordam e proíbem esse tipo de marketing (Zouain \& Hamerski, 2017).

Com o avanço tecnológico, as crianças cada vez mais cedo estão tendo acesso às mídias sociais, sendo que os mais utilizados são o celular e televisão, principalmente para acessarem jogos, brincadeiras, vídeos e a internet. O tempo que elas gastam em frente à tela desses eletrônicos vem crescendo absurdamente segundo estudiosos esse hábito contribui para o sedentarismo tornando-se uma das principais causas da obesidade infantil. Isso porque, a criança deixou de brincar e se movimentar tornando-se um indivíduo sedentário, outrossim, é que a mídia assistida influência diretamente nas escolhas alimentares, uma vez que os anúncios direcionados aos pais e aos filhos em geral contêm apelos emocionais (Rodrigues \& Carmo\& Breda, 2020).

A obesidade infantil é considerada, atualmente, como um dos principais problemas de saúde pública, trata-se de uma epidemia mundial e contribui substancialmente para a morbimortalidade. Portanto, essa doença traz inúmeros problemas para asaúde da criança e esse entendimento é compartilhado por vários pesquisadores na área (Correa et al., 2020).

Estudos abordam o crescimento do número de infantes com sobrepeso tanto em países industrializados, quanto em países em desenvolvimento. Entende-se que o aumento de peso na infância é decorrente de vários fatores e, também, da situaçãosocioeconômica da família. De certo modo, a falta de atividade física juntamente com a ingestão de alimentos não 
nutritivos e extremamente calóricos contribui para aumento de gordura no organismo (Passamani et al., 2018).

O sobrepeso na infância cresceu significativamente nos últimos tempos e uma das causas importantes é o sedentarismo, resultado de horas despendidas diante da televisão e do celular. Um estudo realizado nos Estados Unidos mostrou que crianças com menos de 12 anos assistem em média a 24 horas de televisão por semana e que esse meio de comunicação é o principal veículo na comercialização de alimentos infantis (Passamani et al., 2018).

Neste sentido, a alimentação das crianças é motivo de preocupação por parte das autoridades, uma vez que os hábitos alimentares e o estilo de vida são fatores que contribuem para saúde infantil. Outrossim, é que a alimentação com baixo teor nutricional contribui para ocorrência de doenças.

Nesse aspecto, o objetivo do estudo é discorrer sobre a influência da publicidade sobre as escolhas alimentares voltadasao público infantil. As campanhas de marketing contam com atrativos para seduzir este consumidor, com alto poder de persuasãoe profundo reconhecimento da criança, por meio da utilização de brinquedos, personagens e de marcas registradas (Oliveira \& Poll, 2017).

A pesquisa é de suma importância para sociedade e para os profissionais que atuam diretamente com a alimentação dosindivíduos. A procura por produtos industrializados pela comunidade infantil é uma realidade preocupante, sendo assim, estudossão fundamentais para conscientização das famílias.

\section{Metodologia}

O presente estudo trata-se de uma revisão bibliográfica de caráter descritivo com abordagem qualitativa. Nesse tipo depesquisa busca-se "[...] explicar um problema a contar de referências teóricas publicadas em artigos, livros e dissertações e teses"(Cervo, Bervian \& Silva, 2015, p. 25).

$\mathrm{O}$ aspecto qualitativo é fundamental no tipo de pesquisa por ser indutivo fugindo, portanto, da prática tradicional de se testar hipóteses. As variáveis estudadas pelo método costumam se apresentar por meio de análise dos artigos e revistas selecionadas. Os dados do estudo devem fornecer informações detalhadas sobre a influência do marketing e da publicidade no processo alimentício infantil, bem como suas consequências para a saúde.

O projeto teve a necessidade de explorar acerca de propagandas veiculadas em mídias com conteúdo alimentício, utilizando-se uma abordagem qualitativa, visto que este tipo não se preocupa com representatividade numérica, mas, sim, com o aprofundamento da ilustração da alimentação infantil brasileira.

Os critérios para inclusão dos artigos foram os publicados nos últimos 6 anos que abordam a influência da publicidadena alimentação infantil publicados em revistas eletrônicas com lapso temporal de 6 anos, ou seja, publicados no período de 2015a 2021. Foram incluídos na seleção somente artigos completos, na íntegra, em língua inglesa e portuguesa na qual subsidiaram o referido estudo. Os artigos excluídos são os publicados fora do período estabelecido, textos incompletos e artigos não condizentes com o tema.

As bases de dados utilizadas na pesquisa foram: Biblioteca Virtual em Saúde (BVS), Scientific Electronic Library Online (Scielo) e Literatura Latino-Americana e do Caribe em Ciências da Saúde (LILACS).

Quanto aos descritores utilizados, foram utilizados os combinados, a saber que derivam dos seguintes descritores: marketing de alimentos infantil. Publicidade de alimentos industrializados. Influência da mídia na alimentação.

\section{Resultados e discussão}

\section{O marketing e a publicidade na área alimentícia}

O marketing, enquanto instrumento estratégico, surgiu nos Estados Unidos da América (EUA) e se disseminou por outros países, transformando esse país em uma grande potência econômica e, desde seu surgimento, vem se expandindo em 
vários países. É importante enfatizar que foi nos EUA que surgiram as primeiras universidades que ofertaram o curso de

marketing, procurando tratar dos problemas ocorridos nos processos de vendas e de produção e, assim, os profissionais qualificados ajudaram as empresas a aperfeiçoar o processo de venda (Oliveira, 2021).

De acordo com Dias (2018. p. 41), "podemos situar a constituição do marketing como disciplina acadêmica no início do século XX" [...], com sua constituição foi criando a sua própria característica e assim conquistando a sua independência de disciplina para área de conhecimento.

Em conformidade, Las Casas (2018, p. 30) afirma que "marketing é a área do conhecimento que engloba todas as atividades concernentes às relações de troca, orientadas para a satisfação dos desejos e necessidades dos consumidores." Nesse aspecto, essa ferramenta administrativa não visa apenas a venda do produto, mas principalmente a satisfação do cliente.

O conceito inicial de marketing foi definido no pós-guerra na década de 1950, quando o comércio passou a considerar não somente a qualidade dos produtos e custos competitivos, mas principalmente entender os desejos de seus clientes. No ano de 1970, as empresas passaram a ter departamentos e diretorias específicas para esse conceito, devido a sua ação dentro da organização demonstrar êxito. Assim, essa nova perspectiva transformou radicalmente as relações econômicas entre organizaçãoe cliente. Percebeu-se que a qualidade do produto não era determinante no processo de compra e venda. Os clientes deixaram deser subjetivos e passaram a ser o foco principal nas relações comerciais. A venda passou a ser norteada na busca da satisfação dos clientes (Kotler \& Keller, 2019).

Esse novo consumidor busca por produtos com qualidade e empresas que sejam mais eficientes em seu atendimento. Sendo assim, as empresas atuais direcionam suas ações na busca de satisfação do cliente e, não mais, como foco absoluto a produção. O modelo de venda com base em aspectos de marketing, tem como finalidade a fidelização de clientes. A venda não se concretiza somente pela compra do produto, mas prioritariamente pela satisfação do consumidor em adquirir tal produto (LasCasas, 2018).

Segundo Dias (2016, p. 2) “marketing pode ser entendido como a função empresarial que cria continuamente valor para o cliente e gera vantagem competitiva duradoura para a empresa, por meio da gestão estratégica das variáveis controláveis de marketing: produto, preço, comunicação e distribuição".

O marketing surgiu, portanto, atrelado às questões econômicas e de conquista de espaços na concretização da sociedade globalizada. Nesse aspecto, as empresas na atualidade estão inseridas em uma economia globalizada e não mais local. Sendo assim, uma empresa de São Paulo não tem como concorrentes somente sua localidade, mas todo o mundo. Isso em decorrência da globalização econômica e da rede de internet. "A tecnologia pode ser usada para garantir um diferencial competitivo frente ao mercado (Cavallini, 2018, p.21)".

De acordo com Honorato (2018) a essência do marketing consiste no processo de troca ao se identificar os desejos ou necessidades dos clientes, busca-se sua satisfação, oferecendo-lhe atendimento e produtos que os consumidores desejam. Com essa ferramenta, as organizações foram modificando o seu foco, pois tinham que acompanhar a realidade de cada época, para permanecer viva no mercado que é tão instável, pois no decorrer dos anos surgiram inovações que contribuíram para que o marketing se evoluísse e se tornasse tão importante para as empresas e sociedade.

As empresas perceberam que o marketing não visa só vender produtos, mas tem o objetivo de conhecer os seus clientes tão bem que o produto ou serviço seja adequado ao consumidor de tal forma que se venda sozinho. E assim o marketing foi seexpandindo para outros países, e depois de um bom tempo a filosofia de marketing começou a ser aderida no Brasil. Importante salientar que a ferramenta de marketing se modifica conforme as necessidades sociais, não sendo algo inflexível (Araújo, 2019). Atrelado à esse pensamento, Gorlich (2015) afirma que o marketing é um processo social que 
objetiva a criação, comunicação, entrega e troca de ofertas que têm valor para clientes, empresas e para a sociedade em geral, utilizado por organizações em todo o mundo com o objetivo de persuadir o consumidor dos seus produtos, e a publicidade é uma ferramenta utilizada pelo marketing para promover a venda de produtos, serviços e a divulgação de ideias.

Nesse aspecto, a publicidade envolvendo a alimentação está bem presente na sociedade moderna ao incentivar padrões e hábitos alimentares. As campanhas midiáticas reforçam a alimentação imediatista, baseada em "fast food" subsistindo os alimentos in natura e traz consequências terríveis para a saúde do indivíduo (Ceccato et al., 2018).

O estudo de Rodrigues, Carmo e Breda (2020), enfatiza que a indústria publicitária tem como foco criar lealdade à marca desde idades precoces para que o consumo se mantenha ao longo da vida. Sendo assim, é inegável a influência que as empresas alimentícias imprimem sobre a alimentação familiar brasileira.

O poder de persuasão das propagandas pode influenciar tanto adultos quanto crianças ao consumo dos alimentos divulgados em comerciais, sendo estes em sua maioria ultraprocessados. Entende-se que a infância é um momento especial no desenvolvimento humano e é nessa fase que os hábitos alimentares são consolidados. Nesse aspecto, fica evidente o impacto dascampanhas publicitárias com alimentos ultraprocessados para o consumo infantil (Almeida, 2015).

Os alimentos industrializados consistem em produtos formulados principalmente ou inteiramente a partir de ingredientes processados (por exemplo, pão, batatas fritas, biscoitos, doces, chocolate, refrigerantes, cereais matinais e carne processada) (Rauber et al., 2015).

O estudo de Silva e Vasconcelos (2018) associa o crescente consumo de alimentos pouco nutritivos às configurações e papéis familiares e sociais atuais que buscam por praticidade. Assim, fica evidente que mudanças ocorridas na família e sociedade reforçam os estímulos do marketing e mídia no comportamento alimentar infantil, justificados pelo poder persuasivo das propagandas televisivas voltadas para esse público e, principalmente, ao maior acesso à essas publicidades devido ao uso frequente das tecnologias avançadas.

O acesso às mídias pela criança acontece cada vez mais cedo, sendo assim, a infância sofre com a influência direta da publicidade no ramo alimentício, destacando que as mais presentes não enfatizam uma alimentação saudável. Portanto, é fundamental repensar sobre o marketing e alimentação principalmente em relação à criança (Florêncio \& Reikdal, 2019).

Em pesquisa realizada em uma escola ficou evidente que $44 \%$ das crianças assistem por um período de 2 horas diáriasde televisão e $56 \%$ até 4 horas ou mais. Em contrapartida, dos entrevistados $72 \%$ optam por lanches industrializados, o que se vislumbra a influência da publicidade alimentícia sobre as escolhas alimentares. (Ceccato et al., 2018).

Em conformidade o Ministério da Saúde (2019) afirma que a cada três crianças uma está acima do peso, o que é um número alarmante, isso em detrimento de vários fatores, mas prioritariamente pela mudança nos hábitos alimentares e pela indução da mídia sobre o estilo fast food, atrelado ao sedentarismo.

Importante ressaltar que a publicidade de alimentos ultraprocessados e com baixo valor nutritivo não pode ser a única responsável pela obesidade infantil, no entanto, a influência das propagandas alimentícias na alimentação infantil é inquestionável. Diante disso é fundamental a criação de políticas públicas que atuem de forma educativa e restritiva nos moldesabusivos publicitários (Passamani et al., 2018).

Sobre o poder do marketing e da propaganda voltado ao público infantil é preciso que as leis em vigor se tornem mais rígidas no controle das informações voltadas para o público infantil, associada à conteúdos de promoção de saúde, e que a população se torne mais participativa para que esse tipo de propagandas seja denunciado ou nem sejam divulgadas (Caivano et al., 2020).

\section{O acesso às tecnologias e mídias sociais pelo público infantil}

Analisando a terminologia tecnologia, ela vem do verbo grego tictein que significa criar. Para os gregos era o 
conhecimento prático que objetivava um fim concreto. Sendo assim confirma-se que a tecnologia sempre esteve presente na vidado homem (Levy, 2018).

Antes do século XX, a tecnologia era vista somente como método científico que cria e/ou transforma processos materiais. Já no século XX, exatamente na década de 50, o termo passa a incorporar outros meios, processos e ideias, surge, portanto, um novo conceito. Verifica-se que a relação do homem e a tecnologia modificam-se aos poucos de acordo com o desenvolvimento social, atualmente não podemos dissociar ciência e tecnologia. Ressaltando que o homem depende desses avanços tecnológicos para sua sobrevivência no mundo globalizado (Sancho, 2017).

Evidencia-se que cada vez mais a sociedade interage com as inovações tecnológicas, isso significa, que as relações sociais atuais são bem diferentes das décadas passadas, a tecnologia faz-se presente fortemente na sociedade moderna. A cultura

brasileira está sendo moldada pelo crescimento do consumo de recursos digitais, uma gama de tecnologias necessárias ao trabalhoe vida em sociedade (Sancho, 2017).

O avanço das tecnologias de informação e comunicação tem papel fundamental no desenvolvimento da sociedade. A sociedade moderna é caracterizada pelo crescimento da tecnologia, pela revolução das ferramentas de comunicação e pela evolução da informática. Entende-se que a tecnologia sempre acompanhou a história da humanidade, portanto, é fruto da ação e do conhecimento do humano. O homem passou a utilizar as novas tecnologias para satisfazer suas necessidades e para facilitar o seu trabalho, esse entendimento permeou por muitos anos, isto é, o avanço tecnológico está associado ao sistema de crescimentodigital (Sancho, 2017).

As tecnologias da informação e da comunicação são frutos das transformações sociais, na qual o ser humano utilizando-se do conhecimento passa a produzir ferramentas e instrumentos que modificam seu modo de viver. $\mathrm{O}$ fato de a tecnologia fazerparte da cultura do homem demonstra que ela existe desde a criação da humanidade, porém apresentam-se de forma diferenciadaa cada época (Levy, 2018).

$\mathrm{Na}$ atualidade, acredita-se que esse desenvolvimento no campo das tecnologias tem sido significativo, isso em detrimento do grande investimento que se faz na área tecnológica. Sendo assim, a sociedade convive com o crescimento do número de informações e produtos tecnológicos. A tecnologia tem impacto diretamente na sociedade como cita Nunes (2017) as mudanças ocorridas no processo de produção repercutem na ação humana. Os avanços tecnológicos contribuíram efetivamente para o desenvolvimento e perfil de uma nova sociedade.

O século XXI retrata um mundo globalizado dependente das inovações tecnológicas emergido em uma cibercultura. NoBrasil o avanço tecnológico tem acontecido com um certo atraso em relação aos países mais desenvolvidos. Na atualidade é difícil imaginar-se sem celular ou computador, são as "mordomias tecnológicas" produtos estes que não faziam parte do cotidianodos povos da antiguidade. Com o passar dos tempos as tecnologias têm se aprimorado cada vez mais, não somente no campo técnico, mas principalmente em conhecimento e informação (Simão Neto et al., 2017).

As crianças também acompanham essas mudanças tecnológicas de maneira muito intensa, o que trouxe inúmeros prejuízos à saúde infantil. Percebe-se que as brincadeiras com movimentos foram substituídas pelo tablets ou pela TV, como consequência a alimentação já é reflexo das influências digitais e não a recomendada pela família (Santos et al., 2020).

A infância é o momento das atividades lúdicas constantes. Por meio delas, as crianças satisfazem grande parte de seus desejos particulares. Ao brincar, observa-se a satisfação que elas experimentam ao participarem das atividades. Sinais de alegria,risos, certa excitação são os componentes desse prazer, embora sua contribuição vá muito além. É importante salientar que por meio da brincadeira eles exercitam as suas relações sociais e culturais (Petri \& Rodrigues, 2020).

Em conformidade, Petri e Rodrigues (2020, p. 10) afirmam que "o brincar é uma atividade que auxilia na formação, socialização, desenvolvimento de habilidades psicomotoras, sociais, físicas, afetivas, cognitivas e emocionais". Ao brincar as 
crianças expõem seus sentimentos, aprendem, constroem, exploram, pensam, sentem, reinventam e se movimentam.

As crianças, na sociedade moderna, ao interagirem com as tecnologias e mídias, modificam suas práticas lúdicas passando a internalizar as brincadeiras virtuais. Sendo assim, o acompanhamento da família nesse processo é fundamental para uma inserção tecnológica saudável (Santos et al., 2020).

É necessário que pais e educadores reflitam sobre as mudanças ocorridas no processo de brincar da criança, bem comoo reflexo da tecnologia no cotidiano infantil. Se por um lado as mudanças tecnológicas propiciam conforto e praticidade à sociedade, é importante ressaltar que o uso de recursos digitais contribui significativamente para um estilo de vida sedentário e menos ativo, o que prejudica à saúde humana (Santos et al., 2020).

De certo modo, além da falta de movimentação das crianças, estudiosos como Kishimoto (2018) enfatizam que as brincadeiras tecnológicas limitam o pensamento e a criatividade infantil, isso porque não há um exercício mental, pois o conteúdojá está pronto, a criança não precisa exercitar sua cognição. Outrossim, é que a rede sem delimitação dos pais rompe com os preceitos infantis, isso porque a criança acessa conteúdo do mundo adulto.

Importante salientar, que os brinquedos e jogos virtuais são importantes para inclusão social da criança, não há como viver distante dessa realidade digital. No entanto, é necessário ponderar e acompanhar a criança no uso dessas tecnologias. Destacando, que as brincadeiras com videogames, tablets ou desenhos na TV não podem substituir o entretenimento com atividades como o futebol, a boneca, os carrinhos, entre outros, pois isso tem um impacto significativo na formação do desenvolvimento físico e cognitivo da criança (Lacerda, 2021).

Segundo Cotonhoto e Rossetti (2016), a geração de crianças que nasceram na revolução da informação, já está submersas em um mundo repleto de novidades que, a priori, traz conforto e praticidade na forma de comunicar por meio da portabilidade, dos serviços de telefonia móvel e dos serviços de streaming, que mais recentemente surgiram para concorrer comos serviços de TV aberta e a cabo.

Mesmo sabendo que a criança nasce inserida nesse contexto digital, Cotonhoto \& Rossetti (2016) destacam a escassez de estudos que discorrem sobre a participação infantil cada vez mais cedo no universo tecnológico, bem como suas consequênciasà saúde e desenvolvimento infantil. É inegável o uso de tecnologias em todas as faixas etárias, nesse sentido, o aprimoramento de estudos evidenciando os seus efeitos é imprescindível.

O acesso à televisão, primeiramente, e depois ao celular, acabaram trazendo conforto e comodidade, contudo, o uso indiscriminado por parte da população pode ser responsável por diversas modificações cognitivas e comportamentais não tão benéficas (Prodanov \& Cimadon, 2016).

O uso abusivo das tecnologias, pode gerar problemas na aprendizagem, aumento da impulsividade, atraso no desenvolvimento da criança, alterações do sono e inclusive aumentar as taxas de depressão e ansiedade infantil, déficit de atençãoe outras complicações. Tais problemas podem ser de ordem social, cognitiva e afetiva e assolam geralmente a geração imersa nas tecnologias digitais, que já nasceram inseridas em um mundo onde os adultos também fazem uso excessivo de celulares, principalmente (Menger-ogle et al., 2018).

\section{A obesidade na primeira infância decorrente da má alimentação}

A prevalência de obesidade está crescendo rapidamente em todo mundo e, diretamente proporcional à ela, estão os fatores de risco para doenças cardiovasculares-DCV e distúrbios metabólicos. Estudos em vários países têm mostrado que a o excesso de peso é um sério problema de saúde coletiva, um estudo na Austrália mostrou que pessoas obesas apresentaram significativamente mais fatores de risco para DCV; dentre eles estão: pressão arterial elevada, lipoproteínas de alta densidade- HDL em baixos níveis, colesterol total e lipoproteínas de baixa densidade-LDL em altos níveis (Rech, 2017).

Segundo Barreto et al. (2018, p. 7) “a obesidade é uma doença crônica, que envolve fatores sociais, 
comportamentais, ambientais, culturais, psicológicos, metabólicos e genéticos. Caracteriza-se pelo acúmulo de gordura corporal resultante do desequilíbrio energético prolongado, que pode ser causado pelo excesso de consumo de calorias e/ou inatividade física".

O excesso de peso normalmente está associado a fatores genéticos ou ambientais, sendo sedentarismo, e os maushábitos alimentares seus fatores potencializadores. Um peso acima da eutrofia e baixo condicionamento físico constituem problemas à saúde e estão afetando um número crescente de indivíduos cada vez mais jovens. Em conformidade Mendonça (2019, p. 42) afirma que obesidade "é um estado de adiposidade no qual o peso corpóreo está acima do ideal ou classificado pela OMS comoo alto grau de armazenamento de gordura no organismo que está associado a riscos para a saúde, por sua relação com várias complicações metabólicas".

O índice de massa corporal (IMC) é recomendado para a medida da obesidade em nível populacional e na prática clínica. Esse índice é estimado pela relação entre o peso e a estatura, e expresso em $\mathrm{kg} / \mathrm{m}^{2}$. O excesso de gordura e a sua distribuição nocorpo interferem nos riscos associados ao excesso de peso. Quando o excesso de gordura corporal é situado predominantementena região abdominal, representa maior risco (Mendonça, 2019).

A constatação de peso acima do ideal está associada prioritariamente aos hábitos da vida moderna, que contribuem paradiminuir o gasto energético por meio do uso de meios de transportes que se opõem a caminhadas diárias para escola e trabalho, por exemplo. Essas mudanças de hábito tornaram-se um dos principais fatores para o acúmulo de peso corpóreo em todas as idades, principalmente para população urbana (Machado, Ferreira \& Rangel, 2019).

Nos dias atuais, é perceptível que jovens e adultos passam muitas horas inativos e consumindo algum tipo de alimento, geralmente industrializados por ser prático seu consumo, porém são alimentos ricos em muita gordura, sal e açúcares. Nesse aspecto, a prevalência do crescimento do sobrepeso e da obesidade no Brasil representa um dos principais desafios de saúde pública neste século e cresceu de forma significativa nas últimas três décadas (Rech, 2017).

Um dos fatores de maior risco que contribuem para o óbito precoce em adultos é a obesidade. A prevenção desde a infância, passando pela adolescência até a vida adulta, acompanhada de um diagnóstico precoce, é uma forma de incentivar a promoção da saúde e redução da morbimortalidade. Além de ser um fator de risco importante para outras doenças, interfere na longevidade e qualidade de vida, e ainda apresenta implicações na aceitação social por ser motivo de discriminações em locais onde a valorização da estética se sobrepõe na sociedade contemporânea (Machado, Ferreira \& Rangel, 2019).

Considera-se que as mudanças de comportamento social, alimentar e o hábitos de vida sedentário atuam sobre genes desuscetibilidade e contribuem como fator determinante para o crescimento da obesidade no mundo. Estudos vêm mostrando umaprevalência maior do fenômeno da obesidade em indivíduos de classe econômica mais alta. Segundo o estudo de Ronque et al. (2018) o alto nível socioeconômico pode afetar a prevalência de excesso de peso, aumentando os riscos de desenvolvimento dedistúrbios metabólicos.

A sociedade está exposta ao conceito de que a gordura e o excesso de peso representam um problema de autocontrole esofre com clara discriminação de vários setores, como nas escolas, trabalho e meios sociais. Os obesos de todas as idades são vítimas de um ciclo vicioso de baixa autoestima, depressão, rejeição social, superalimentação e, consequentemente, aumento dagordura corporal (Ronque et al., 2018).

Nesse sentido, Machado, Ferreira e Rangel (2019) relatam que a obesidade infantil é um problema de saúde pública, tendo prevalência entre os 2 a 18 anos e tem crescido significativamente, chegando a mais de 100 milhões de crianças afetadas em 2015. Diversos fatores contribuíram para esse crescimento, como fatores genéticos, psicológicos, econômicos, sociais e principalmente a ausência de hábitos alimentares saudáveis e a prática de exercício físico escassa.

A alimentação saudável é uma prática imprescindível para redução de casos de obesidade infantil. Portanto, propiciar àcriança e ao adolescente uma dieta balanceada em nutrientes aliada à prática de atividades, nesse quesito a brincadeira ao ar 
livreé fundamental e reduz o índice de gordura corporal (Karnopp et al., 2019).

Torna-se necessário, adotar medidas educacionais, tanto para as crianças quanto para os seus cuidadores, a fim de reduzir a permanência das crianças em frente à televisão, incentivar hábitos alimentares mais saudáveis e a prática de atividades físicas.Além disso, é fundamental também criar estratégias de regulamentação de propagandas destinadas ao público infantil e aumentara fiscalização para o cumprimento das normas estabelecidas (Wang, 2016).

\section{A alimentação e a influência da mídia nas escolhas infantis}

Estudos apresentam uma relação entre a alimentação inadequada e publicidade enfatizando o novo comportamento de consumo das crianças e suas implicações. Henriques, Sally e Burlandy (2020) afirmam que as crianças dentrode seu núcleo familiar, participam efetivamente das escolhas no processo de compra representando $70 \%$ das decisões e especialmente nas compras alimentares esse percentual atinge os $92 \%$.

A publicidade de alimentos faz parte da realidade da criança que é influenciada pelo novo estilo de alimentos. A exposição ao marketing alimentar pode influenciar de diversas formas no comportamento alimentar das crianças, daí a necessidade de acompanhamento da criança pelo cuidador no uso de equipamentos digitais (Rodrigues \& Carmo \& Breda, 2020).

A criança, antes dos 4 ou 5 anos, não possui capacidade de distinguir as propagandas da programação. Entre os $5 \mathrm{e}$ os 7 anos, são capazes de fazer a distinção, mas só após os 11 ou 12 anos constroem pensamento crítico acerca da publicidade e de suas intenções (Rodrigues \& Carmo \& Breda, 2020).

Os recursos tecnológicos, associados ao imediatismo, são companheiros prediletos das crianças, exercendo papel importante no processo de socialização. A influência das propagandas publicitárias nas práticas alimentares é uma realidade inegável, ou seja, a criança fica exposta ao que a mídia fala, exibe e ensina e são expostas cada vez mais cedo a uma alimentação desequilibrada, pobre em nutrientes e excessivas em calorias. O marketing de alimentos e bebidas pode influenciar no consumoe nas preferências alimentares das crianças, e, contribui para obesidade infantil, uma vez que são produtos ricos em gordura e açúcares (Zouain \& Hamerski, 2017).

Caivano et al. (2020) afirma que o conteúdo produzido através da indústria de marketing alimentício com a utilizaçãode imagens e mensagens podem mascarar a realidade como forma de atingir seu objetivo, já que as estratégias de marketing sensorial proporcionam benefícios para a marca e para seus clientes, seja usuários, intermediários ou recomendadores.

Segundo Dias, Silva e Souza (2020, p.106):

[...] o processo utilizado pelo marketing, pelas empresas para persuadir o consumo de seus produtos, que abrange o planejamento, a concepção, a atribuição do preço, a promoção e a distribuição de bens, serviços e ideias e a publicidade é a ferramenta utilizada pelo marketing para promover a venda de seus produtos, é uma forma de comunicação com o objetivo de promover a comercialização ou alienação.

Associado a esse entendimento, Pimenta, Rocha \& Marcondes (2015) consideram que as estratégias de marketing objetivam seduzir a criança para o consumismo alimentar, utilizando-se de abordagens emocionais e afetivas, bem como a oferta de brindes utilizando-se de personagens e apresentadores infantis a fim de atrair a atenção das crianças para $o$ consumo de seus produtos. A técnica de apelo mais frequente consiste no uso de animações, que prendem a atenção da criança. Além disso, o marketing tem usado crianças como protagonistas dos comerciais de alimentos, focando no público.

Baseado no que assistem nos comerciais, as crianças são influenciadas a acreditar que os alimentos 
ultraprocessados têm mais qualidade, são mais saborosos e tornam as pessoas mais felizes, fortes, atraentes e socialmente aceitas (Henrique, Sally \& Burlandy, 2020).

Domiciano (2020) em seu estudo analisou 154 propagandas de alimentos transmitidos na internet e na televisão e evidenciou que o principal apelo comercial utilizado foi o estímulo do objeto de comer $(21,1 \%)$, seguido de ilusão/fantasia (13,9\%), família/ amizade $(13,2 \%)$ e sabor $(13,2 \%)$. Contrariamente, os recursos menos utilizados foram: o apelo nutricional/dietético ( $2 \%$ das propagandas); o preço $(1,7 \%)$ e a conscientização que representou apenas $1 \%$ de todas as propagandas analisadas.

Em conformidade, o estudo de Fidelix (2020) com 102 escolares de 7 a 10 anos, concluiu que a mídia influencia nas escolhas alimentares das crianças, principalmente quando vinculadas à imagem de artistas, músicas e personagens animados nos comerciais. Se evidenciou ainda que produtos com embalagens de cores atrativas e modelos diferenciados, alguns contendojogos e brinquedos, são os preferidos das crianças.

Segundo Engler, Guimarães e Lacerda (2016), as campanhas publicitárias na área da alimentação, hoje, constroem uma nova realidade, tida como novo padrão alimentício baseado em comidas rápidas que trazem alegria e bem-estar. Na verdade, o consumo de alimentos ultraprocessados pela criança traz problemas à saúde, principalmente a obesidade infantil.

Para Lopez (2015) o efeito hipnótico que alguns aparelhos eletrônicos têm sobre crianças, adolescentes e jovens pode ser considerado pelos mais velhos como incomum, mas existe uma explicação de cunho científico. A nomofobia é o medo irracionalem estar distante de formas de comunicação baseadas no uso de aparelhos eletrônicos e redes sociais, substituindo a comunicaçãointerpessoal e o uso da linguagem verbal (oralizada).

Desta forma, o processo comunicativo que poderia ser verbalizado, fica limitado em notificações de mensagens recebidas em um loop de distração, pois as notificações são responsáveis por gerar uma descarga de dopamina no cérebro humano. Entende-se que a notificação mediante o som de uma mensagem em mídias sociais provoca no ouvinte uma elevada excitação e o cérebrolibera dopamina, apresentando uma sensação de recompensa positiva (Lopez, 2015).

Já na interrupção e proibição do uso do celular, é provocado na criança um efeito contrário, ou seja, é liberado o cortisol, hormônio responsável por gerar estresse, tédio e impulsividade, fatores estes que possuem relação direta com os hábitos alimentares da população. Efeito similar ocorre quanto ao uso da televisão (Pereira, Nogueira \& Vecchio, 2020).

Nesse sentido, é importante citar o estudo de Pereira, Nogueira e Vechio (2020), isso porque em sua pesquisa ficou evidenciado que o celular é a ferramenta digital mais utilizada pelas crianças, totalizando 71,1\% das crianças e 91,9\% dos adolescentes em um universo de 100 entrevistados. Portanto, o celular, assim como outras mídias possibilitam acesso da criança/adolescente a páginas como Youtube ou redes sociais onde estão presentes campanhas publicitárias que envolvem produtos alimentícios.

Já as que incentivam a alimentação saudável, estão em número reduzido ou quase inexistentes, muitas vezes somente governamentais. Sendo assim, o conteúdo produzido pelas campanhas relativas a alimentos com utilização de ultraprocessados mascaram a verdadeira realidade no que diz respeito aos nutrientes fornecidos pelo produto e contribui para um hábito alimentarinadequado (Domiciano, 2020).

Neste sentido, a ausência de disciplina, acompanhamento dos pais e o excesso de estímulos negativos para o cérebro fazem com que a compulsão alimentar seja uma realidade das famílias brasileiras, e de forma ainda mais preocupante, das crianças (Wang, 2016).

\section{A influência da mídia na alimentação infantil: análise da legislação brasileira}

A Legislação brasileira ainda não possui norma específica que regulamente a publicidade destinada a crianças e adolescentes. No entanto, existem preceitos quanto à publicidade descrita na Carta Magna de 1988, no Código do Consumidor, 
no Estatuto da Criança e do Adolescente-ECA e outras leis complementares (Dias, Silva \& Souza, 2020).

A presença de lei específica que limite campanhas publicitárias destinadas a crianças é uma necessidade em nosso país, no entanto, faz-se necessário que os pais adotem medidas educativas quanto ao uso da tecnologia, bem como a prática de hábitos alimentares saudáveis (Dias, Silva \& Souza, 2020).

Importante salientar que mesmo havendo projetos de lei que visem controlar e limitar a publicidade para o público infantil, torna-se imprescindível a participação das famílias no controle e acompanhamento dos filhos, isso porque o público infanto-juvenil permanece muito tempo conectado à internet (Who, 2015).

O Conselho Nacional dos Direitos da Criança e do Adolescente (CONANDA), órgão brasileiro, possui políticas que visam a proibição de publicidades demasiadamente influentes às crianças, porém não basta proibir é fundamental haver fiscalização. O Projeto de Lei $n^{\circ}$ 5.921/2001 veda a publicidade direta ao público infantil em detrimento da ausência de discernimento crítico. Já a Resolução no 163/2014 dispõe sobre a proibição de publicidade abusiva a crianças e adolescentes em creches e escolas (Dias, Silva \& Souza, 2020).

Com o objetivo de incentivar a alimentação saudável tem-se a Resolução nº 408/2008 do Ministério da Saúde na qual apresenta diretrizes que contemplam os benefícios para a saúde de alimentos saudáveis. Nesse aspecto, a imposição legal deve acontecer em dois aspectos, tanto o de fiscalização quanto o educativo (Brasil, 2019).

A Agência Nacional de Vigilância Sanitária (ANVISA) publicou em 15 de junho de 2010 a resolução de no 24 que proíbe qualquer publicidade que tenha divulgação de produtos alimentícios com alta quantidade de açúcares, gorduras trans, saturadas, sódio e com baixo teor nutritivo para público infantil em meios de comunicação, com o intuito de reduzir a obesidade infantil e outras doenças. No entanto, essas campanhas ainda são vistas todas as mídias digitais. Portanto, falta fiscalização por parte dos órgãos responsáveis para proibir esse tipo de marketing (Engler, Guimarães \& Lacerda, 2016).

A Lei $n^{\circ}$ 8985/2012, do município de Florianópolis, prevê a não comercialização de lanches acompanhados de brinde ou brinquedo. Entende-se que a brincadeira faz parte da essência da infância, atrelar ao produto alimentício um chamariz, aumenta a probabilidade de consumo do produto pelo infante.

Estudos como o de Ferreira et al. (2015) demonstram que a maioria dos alimentos industrializados consumidos por crianças apresenta o uso de desenhos animados, animais e/ou mascotes, além de letras chamativas e palavras no diminutivo. É possível observar, também, que os produtos destinados às crianças utilizam maior número de estratégias de convencimento do que os destinados a outros públicos.

Diante disso, a Organização Mundial de Saúde (OMS) afirma a necessidade de extinguir a publicidade que envolve alimentos não saudáveis para crianças e adolescentes. Por meio de normativas e orientações, a OMS incentiva os governos a investirem em políticas públicas que minimizem os desastres provocados pela publicidade de alimentos ricos em sódio, açúcares e gorduras (Engler, Guimarães \& Lacerda, 2016).

O Código Brasileiro de Autorregulamentação Publicitária, órgão criado pelo Conselho Nacional de Autorregulação Publicitária (CONAR), institui a proibição de campanhas publicitárias com alimentos que influenciam no consumo infantil, bem como a utilização de personagens do universo pueril. Sendo assim, mesmo não havendo lei específica, o Brasil possui regulamentações importantes sobre a temática, porém, percebe-se que a fiscalização é ineficaz (Ceccatto et al., 2018).

\section{Considerações Finais}

O presente estudo identificou que as campanhas publicitárias possuem forte influência nos hábitos alimentares e no estilo de vida das crianças, uma vez que divulgam produtos alimentícios utilizando ferramentas atrativas à faixa etária como desenhos, músicas e brincadeiras. Percebe-se ainda que alguns alimentos são comercializados com brinquedos ou embalagenscom jogos, tornando-se ainda mais atrativos e aguçando o desejo por produtos que em sua maioria têm baixo ou 
nenhum valornutricional.

Evidenciou-se que mesmo havendo leis ou normativas que proíbam a publicidade de alimentos inadequados ao público infantil, essa prática ainda é bem presente. Sendo assim, a participação da família quando a criança navega pelo mundo digitalé uma importante estratégia para reduzir os impactos gerados nos hábitos alimentares dessa faixa etária.

É imprescindível reafirmar a importância da educação e da percepção de saúde na família e escola no que diz respeitoà construção dos hábitos alimentares saudáveis, bem como, o incentivo à prática de atividades recreativas a fim de reduzir os impactos gerados pelo consumo de alimentos fontes de gorduras e açúcares bombardeados pela mídia.

O rompimento com o sedentarismo também é de extrema importância, sugere-se a introdução da educação nutricional na infância com o intuito de incentivar a prática de uma alimentação balanceada, pois as escolhas feitas nesta fase podem perdurar na vida adulta. Dessa maneira, salienta-se a importância de um profissional nutricionista na formação de hábitos e práticas alimentares saudáveis, garantir melhor qualidade de vida na infância e posterior vida adulta.

A restrição da publicidade para o público infantil deve dialogar com outras agendas regulatórias, focadas primordialmente na proteção do interesse público e no direito à informação, garantidos no ordenamento jurídico brasileiro.

Torna-se evidente, por meio do estudo realizado, que a publicidade de alimentos não saudáveis direcionados à infânciainfluencia diretamente na escolha das crianças. Portanto, é fundamental que as famílias assumam a responsabilidade em limitar o uso das tecnologias e que o governo regulamente os limites das empresas responsáveis por campanhas de marketing e efetivetais normativas por meio de fiscalizações efetivas, pois a alimentação saudável é um direito da criança e deve ser assegurada em sua totalidade, evitando influências publicitárias que mitigam alimentos ausentes de requisitos nutritivos.

Sendo assim, sugere-se para futuros trabalhos o aprofundamento sobre os impactos do marketing alimentício no hábito alimentar das crianças com dados estatísticos para melhor visualização da problemática. Portanto, incentivar pesquisas que discorram sobre o papel da família para minimizar os malefícios causados por campanhas publicitárias que apresentam alimentos sem qualidade nutricional ao público infantil.

\section{Referências}

Almeida, L. B. (2015) O ambiente alimentar, os indivíduos e suas práticas: um estudo no município de São Paulo. Tese de Doutorado. Universidade de São Paulo. 2015. https://teses.usp.br/teses/disponiveis/6/6138/tde-17112015105844/pt- br.php.

Araújo, L. C. G. (2019) Teoria Geral da Administração: Aplicação e resultados nas empresas brasileiras. Ed. Atlas.

Barreto, A. G. S. (2018). Hábitos obesogênicos e prevalência de obesidade em população adulta na Bahia. Revista Brasileira de Obesidade, Nutrição e Emagrecimento, São Paulo 3(14), 165-174. https://ares.unasus.gov.br/acervo/handle/ARES/20050.

Brasil (1988), Constituição Federal de 1988. http://www.planalto.gov.br/ccivil_03/constituicao/constituicao.htm

Brasil (2019). Ministério da Saúde. Secretaria de Atenção à Saúde. Departamento de Atenção Básica. Guia Alimentar para a População Brasileira.Brasília. https://bvsms.saude.gov.br/bvs/publicacoes/guia_alimentar_populacao_brasileira_2ed.pdf.

Caivano, S. \& Lopez, R, F. \& Sawaya, A. L. (2020). Conflitos de interesses nas estratégias da indústria alimentícia para aumento do consumo de alimentos ultraprocessados e os efeitos sobre a saúde da população brasileira. DEMETRA: Alimentação, Nutrição e Saúde. 12(2), 348-360. http://www.epublicacoes.uerj.br/index.php/demetra/article/view/26928

Cavallini, R. (2018). O marketing depois de amanhã: explorando novas tecnologias para revolucionar a comunicação. Ed. do Autor.

Ceccatto, D. \& Spinelli, R. B. \& Zanardo, V. P. S. \& Ribeiro, L. A. (2018). A influência da mídia no consumo alimentar infantil: uma revisão da literatura. PERSPECTIVA, Erechim. 42, 141-149, março/2018. https://www.uricer.edu.br/site/pdfs/perspectiva/157_700.pdf.

Cervo, A., Bervian, P. A. \& Silva, R. (2015) Metodologia Científica. Ed. Pearson.

Corrêa, V. P. \& Paiva, K. M. \& Besen, E. \& Silveira, D. S. \& Gonzáles, A. I. \& Moreira, E. \& Ferreira, A. R. \& Miguel, F. Y. O. M. \& Haas, P. (2020). O impacto da obesidade infantil no Brasil: revisão sistemática. Revista Brasileira de Obesidade, Nutrição e Emagrecimento. São Paulo. 14(85), 177-183. Mar./Abril. 2020. https://www.researchgate.net/profile/Fernanda-Yasmin- Padilha/publication/344729071_O_impacto _da_obesidade_infant il_no_Brasil_revisao_sistematica/links/5fdcbbad92851c13fe9c1609/O-impacto-da- obesidade-infantil-no-Brasil-revisao-sistematica.pdf.

Cotonhoto, L. A. \& Rossetti, C. B. (2016). Prática de jogos eletrônicos por crianças pequenas: o que dizem as pesquisas recentes?. Rev. Psicopedagogia. 33, 346-57. http://pepsic.bvsalud.org/scielo.php?script=sci_arttext\&pid=S0103-84862016000300012. 
Dias, R. (2009). Marketing ambiental: ética, responsabilidade social e competitividade nos negócios. Ed. Atlas.

Dias, M. C. R. \& Silva, P. H. De P. Da \& Souza, a. M. de. (2020). Influência da publicidade no desencadeamento da obesidade infantil no Brasil. Rev. Episteme Transversalis. Volta Redonda-RJ. 11(3), 2236-2649. http://revista.ugb.edu.br/ojs302/index.php/episteme/article/view/2181

Domiciano, C. G. (2020). Estratégias da mídia e os apelos comerciais para promoção dos produtos alimentícios. Revista Ciências em Saúde, 4(1), 316- 328. http://186.225.220.186:7474/ojs/index.php/rcsfmit_zero/article/view/163.

Engler, R. C. \& Guimarães, L. H. \& Lacerda, A. C. G. (2016). Design e consumo: a influência da mídia sobre a obesidade infantil. Blucher Design Proceedings, 9(2), 5625-5637. http://pdf.blucher.com.br.s3-sa-east-1.amazonaws.com/designproceedings/ped2016/0529.pdf.

Ferreira, J. S. G. \& Silva, Y. Da \& Moraes, O. M. G. de.\& Tancredi, R. P. (2015). Marketing de alimentos industrializados destinados ao público infantil na perspectiva da rotulagem. Vigilância Sanitária Em Debate: Sociedade, Ciência \& Tecnologia (Health Surveillance under Debate: Society, Science \& Technology) - Visa Em Debate..3(2), 75-84. https://doi.org/10.3395/2317-269x.00293.

Fideliz, F. H. N. (2020). A influência da mídia nos hábitos alimentares de crianças em uma escola no município de Cariacica. Trabalho de Conclusão deCurso da Faculdade Católica Salesiana.http://www.catolica-es.edu.br/fotos/files/TCC-2015-1_Flavia.pdf.

Florêncio, L. O. \& Reikdal, C. (2019). A obesidade como consequência da publicidade de alimentos e a proteção da legislação brasileira ao públicoinfantil. Revista Eletrônica da ESA/RO. Destemidos Pioneiros. 12, 1-19. http://revistaesa.oab- ro.org.br/gerenciador/data/uploads/2020/10/Leti\%CC\%81cia-OliveiraFlore\%CC\%82ncio_Cleverton-Reikdal.pdf.

Gorlich, W. (2015). O marketing das emoções. Ed. Mktcognitivo.

Henriques, P. \& Sally, A. O. \& Burlandy, L. (2020). Regulamentação da propaganda de alimentos infantis como estratégia para a promoção da saúde. Temas Livres. Niterói. 17(2), 481-490, 2020. https://doi.org/10.1590/S1413-81232012000200021.

Honorato, G. (2018). Conhecendo o marketing. Ed. Manole.

Jardim, J. B. \& Souza, I. L. (2017) Obesidade infantil no Brasil: uma revisão integrativa. J Manag Pim Heal Care. ISSN 2179-6750, 8(1), 66-90. https://doi.org/10.14295/jmphc.v8i1.275.

Kotler, P. \& Keller, K. L. Administração de marketing. Ed. Pearson Prentice Hall.

Karnop, E. V. \& Vaz, J. S. \& Schafer, A. A. \& Muniz, L. C. \& Souza, R. L. \& Santos, I. Food consumption of children younger than6 years according to the degree of food processing. Jornal de Pediatria, Rio de Janeiro, 93(70), 456-472. https://doi.org/10.1016/j.jped.2016.04.007.

Kishimoto, T. M. (2018). Jogo, brincadeira e a educação. Ed. Cortez.

Lacerda M. B. de. (2021). Um brincar com a tecnologia digital na primeira infância? Reflexões sobre o uso das telas e o processo de integração infantil. Dissertação (Mestrado) - Universidade Católica de Pernambuco. Programa de Pós-graduação em Psicologia Clínica. Mestrado em Psicologia Clínica, 2021. http://tede2.unicap.br:8080/handle/tede/1467.

Las Casas, A. L. (2018). Administração de Marketing: Conceitos, planejamento e aplicações à realidade brasileira. Ed. Atlas.

Levy, P. (2018). Cibercultura. Ed. Coleção TRANS.

Lopez, M. J. M. (2015). Influência do vício, relacionado ao uso de mídias sociais, na extensão dos limites da confiança. Repositório Institucional da Universidade Tecnológica Federal do Paraná. Dissertação de Mestrado apresentada ao programa de Pós-Graduação em Tecnologia, da Universidade Tecnológica Federal do Paraná. http://repositorio.utfpr.edu.br/jspui/handle/1/1935.

Machado, N. De O. \& Ferreira, r. H. \& Rangel, T. L. V. (2019). Obesidade Infantil decorrente da má-alimentação: uma análise à luz da revisão da literatura. Revista Científica Interdisciplinar Multiplos@cessos. , 4(1), 25-40. http://www.multiplosacessos.com/multaccess/index.php/multaccess/article/view/100.

Menger-ogle, A. D.; Johson, A. N.; Morgan, J. A.; Graham, D. J. (2018) Television advertising of food during children's programming in Nepal. Nutrição, 2, 55- 56, https://doi.org/10.1016/j.nut.2018.02.027.

Mendonça, R. T. (2019). Obesidade infantil e na adolescência. Ed. Rideel.

Rech, R. (2017). Obesidade infantil: perfil epidemiológico e fatores associados. Ed. Educs.

Nunes, M. de J. (2019). O professor e as novas tecnologias: pontuando dificuldades e apontando contribuições. Sistemoteca-Sistema de Bibliotecas daUFCG. http://dspace.sti.ufcg.edu.br:8080/jspui/handle/riufcg/5108.

Oliveira, T. S., \& Poll, F. A. (2017). A influência da publicidade na alimentação de escolares e sua relação com o excesso de peso. Cippus, Revista deIniciação Científica. 6 (1), 748-763.http://dx.doi.org/10.18316/cippus.v5i1.2334.

Passamani, C. F. \& Pacifico, g. L. T. \& Lee, O. P. \& Ortiz, J. A. Da R. \& Lopes, F. O. \& Cesario, F. C. (2018). Influência da publicidade na alimentação infantil. Anais Do Salão Internacional De Ensino, Pesquisa E Extensão, 10(2), 1-6. https://periodicos.unipampa.edu.br/index.php/SIEPE/article/view/100261.

Pereira, B. S. \& Nogueira, B. M. \& Vechio, G. H. D. (2020). Comunicação de marca e o público infantil: a influência de anúncios publicitários e ações mercadológicas no cotidiano de crianças e adolescentes. Interface Tecnológica - 17 (2), 325-342. doi.org/10.31510/infa.v17i2.967

Petri, I. S. \& Rodrigues, R. F. L. Um olhar sobre a importância do brincar e a repercussão do uso da tecnologia nas relações e brincadeiras na infância. Research, Society and Development, 9 (9), 1-22. e326997368. https://doi.org/10.33448/rsd-v9i9.7368. 
Pimenta, T. A. M. \& Rocha, R. \& Marcondes, N. A. V. (2015). Políticas públicas de intervenção na obesidade infantil no Brasil: uma breve análise dapolítica nacional de alimentação e nutrição e política nacional de promoção da saúde. Cientista Ciência Biológica Saúde, 17, 1-17. https://doi.org/10.17921/2447$8938.2015 \mathrm{v} 17 \mathrm{n} 2 \mathrm{p} \% 25 \mathrm{p}$.

Prodanov, S. S., \& Cimadon, H. M. S. (2016). A influência da publicidade nos hábitos alimentares de crianças em idade escolar. Revista ConhecimentoOnline, 1,.3-12. https://doi.org/10.25112/rco.v1i0.366.

Rodrigues, A. S \& Carmo, I \& Breda, J. (2020). Associação entre o marketing de produtos alimentares de elevada densidade energética e a obesidadeinfantil. Science Direct. Lisboa. p. 180-187. https://run.unl.pt/handle/10362/104564.

Ronque, E. R. V. \& Cyrino, E. S. \& Dórea, V. \& Júnior, H. S. \& Galdi, E. I. H. G. A. M. (2018). Diagnóstico da aptidão física em escolares de alto nível socioeconômico: avaliação referenciada por critérios de saúde. Revista Brasileira de Medicina do Esporte, 13(2), 71-76. https://doi.org/10.1590/S151786922007000200001

Rauber, F. \& Campagnolo, P. D. B. \& Hoffman, D. J. \& Vitolo, M. R. Consumption of ultra-processed food products and its effects on children's lipid profiles: A longitudinal study. Nutriente Metabólico Cardiovascular.25, 116-122. https://pubmed.ncbi.nlm.nih.gov/25240690/.

Sacho, J. M. (2017) Para uma tecnologia educacional. Ed. Artmed.

Santos, T. A. S. \& Rezende, T. A. \& Santos, I. F. Tonhom, S. F. R. (2020). O acesso a tecnologias pelas crianças: necessidade de monitoramento. RISTI Revista Ibérica de Sistemas e Tecnologias de Informação. 38, 48-63. 48-63. 10.17013/risti.38.48-63.

Simão Neto, A. \& Silveira, M. H. P. \& Costa, M. S. W. (2017). Interação, multimídia e educação. Ed. Ibpex.

Silva, A. M. D. \& Vasconcelos, L. R. (2018). Criança e o Marketing: informações fundamentais para proteger as crianças dos apelos do Marketing Infantil. Ed. Summus Editorial.

Zouain, M. S. \& Hamerski, H. (2017). Número especial Marketing sensorial: o estímulo olfativo como ferramenta de marketing no ponto de venda. Revista Científica Faesa. Vitória, Espírito Santo: 13, s/p. n.2. http://schenautomacao.com.br/ssa7/envio/files/trabalho3_103.pdf.

Wang, T \& Heianza, Y. \& Sun, D. \& Huang, T. \& Ma W. \& Rimm, E. B. \& Manson, J. E. \& Hu FB; Willett W.C. (2016). Improving adherence to healthy dietary patterns, genetic risk, and long-term weight gain: gene-diet interaction analysis in two prospective cohort studies. Departamento de Epidemiologia, Escola de Saúde Pública e Medicina Tropical, Tulane University, New Orleans, LA 70112, EUA. 1136 / bmj.j5644.

Who, W. H. (2015) Ultra-processed food and drink products in Latin America: Trends, impact on obesity, policy implications. PAHO. PanAmerican Health Organization. 4-76. https://iris.paho.org/bitstream/handle/10665.2/7699/9789275118641_eng.pdf. 